\title{
Study on the Performance of High-Speed Rail Damage of Four Different Materials
}

\author{
Jiajie Hu, ${ }^{1,2}$ Wen Zhong $\mathbb{D}^{3}{ }^{3}$ and Qiyue Liu ${ }^{1}$ \\ ${ }^{1}$ Tribology Research Institute, Southwest Jiaotong University, Chengdu 610039, China \\ ${ }^{2}$ AVIC Chengdu Aircraft Industrial (Group) Co., Ltd., Chengdu 610039, China \\ ${ }^{3}$ School of Mechanical Engineering, Xihua University, Chengdu 610039, China \\ Correspondence should be addressed to Wen Zhong; zw1019@126.com
}

Received 5 September 2018; Revised 15 October 2018; Accepted 25 October 2018; Published 2 December 2018

Guest Editor: Mohamed Kchaouu

Copyright ( $\odot 2018$ Jiajie Hu et al. This is an open access article distributed under the Creative Commons Attribution License, which permits unrestricted use, distribution, and reproduction in any medium, provided the original work is properly cited.

\begin{abstract}
For four types of railway rails, corresponding rolling tests have been executed by using the JD-1 wheel/rail simulation device based on the Hertz simulation method, which can ensure the reciprocal contact condition between simulation rail and wheel under experimental conditions approximate to practical contact conditions. The results indicate that, for the rail material which has a higher hardness, the wear volume was less and the plastic deformation layer was thinner after the rolling test, but the crack propagation was more significant and the fatigue damage was severer, showing that its wear resistance was better. The analysis shows that the fatigue resistance of U71Mn rail was better, and considering fatigue is the main failure type for high-speed rail, so it is more suited to the high-speed railway.
\end{abstract}

\section{Introduction}

For transportation of high-speed railway, more and more high demand on the service life of rail has been proposed and rail fatigue has been an important factor influencing the service life of rail. The damage of high-speed rail is different from the damage of heavy rail because the fatigue crack propagation is the main damage mechanism $[1,2]$. In China, transverse fracture occurred in two places due to the oblique crack of rail tread in the high-speed section of Guangzhou-Shenzhen line. Thus, it has great economic significance and scientific value to research the contact fatigue of wheel-rail and the damage of high-speed railway and provide effective preventive measures.

The rolling contact fatigue (RCF) occurred during the rolling contact of a contact pair due to the cyclic force in the contact zone and caused the crack formed on the material surface or subsurface to extend, so material fatigue damage failure occurred [3]. Various countries in the world have done a lot of analyses and researches on the rolling contact fatigue [4]. The rail materials may alleviate wear and surface damage to a significant extent.

Bold et al. thought that the wear rates of both wheel rollers and rail rollers increased with the increase of contact pressure. With the increase of sliding velocity, the wear rates of wheels tend to increase and the wear rates of rails show decrement [5]. It is found by Seo et al. that the ductility and the fracture toughness were two important factors on wear and contact fatigue. The ductility and the fracture toughness of UIC 60 rail steel are higher than those of KS 60 rail steel, so for UIC 60 rail steel, it has a higher resistance to the contact fatigue but has a lower resistance to the wear [6]. Razhkovskiy et al. found that the parameters of damage to the steels, such as the number, dimensions, and area of defects, the angular coefficients of cumulative size statistical distributions of the defects, as well as the velocity of propagation and the attenuation coefficient of ultrasonic waves, have been assessed [7]. Sharma et al. found that bainitic steels have better wear resistance and mechanical properties on account of the typical morphology of bainitic microstructure [8]. The bainitic rail steel, compared to pearlitic rail steel, which has a relatively reasonable combination of wear and fatigue properties, is obtained. For the bainitic rail steel, the initiation and propagation of cracks may be removed partially or entirely during the wear process [9]. Current researches mainly focus on the damage of steel rail from the aspect of wear or fatigue alone but lack the 
research on the coupling relationship between them. However, this study finds that fatigue and wear have a reciprocal relationship. However, this study finds that fatigue and wear have a reciprocal relationship. In this study, based on the coupling relation between wear and fatigue, the rail material suitable for high-speed railway is selected. This study is very important for studying the performance of high-speed rail and reducing rail damage.

In this paper, two kinds of rail steel materials (U71Mn and PD3) used in Guangzhou-Shenzhen line currently were researched. In the test, after these two kinds of steel rail specimens were heat treated differently and were placed on the machine for JD-1 wheel-rail simulation testing to simulate the wheel/rail contact test, they were analyzed and researched by macromorphology, microstructure, hardness analysis, etc. to look for suitable steel for high-speed railway. It provided important reference basis to construct highspeed railway to enhance the security of railway transportation and reduce security risks of railway. It had a great significance for China's railway construction.

\section{Experimental}

The test was conducted on the JD-1 type wheel-rail simulator [10]. In order to insure that the frictional interaction process under test conditions was similar to that on the site, the average contact stress between the simulated wheel and the rail samples and the ratio of semimajor axis to semiminor axis of the ellipse in the contact area under laboratory conditions were set to be same to those on the site according to Hertz contact theory. The small wheel sample was taken from the rail head, and its end surface was parallel to the rail tread. The diameter of the small wheel sample was $62 \mathrm{~mm}$, and the diameter of the big wheel sample was $1153 \mathrm{~mm}$. The materials of simulated small wheels were quenched PD3, hot-rolled PD3, quenched U71Mn, and hot-rolled U71Mn rail materials, respectively.

Table 1 shows the chemical composition and the mass fraction of rail materials. For the material of the simulated large wheel, the mass fraction of carbon was $0.62 \% \sim 0.77 \%$ and HV0.2 $\geq 241 \mathrm{~N} / \mathrm{mm}^{2}(\mathrm{MPa})$. For the test parameters, the simulated speed was $160 \mathrm{~km} / \mathrm{h}$, the weight of the simulated axis was $25 t$, the friction coefficient was 0.2 , and the cycle number of the simulated large wheel was $1.0 \times 106$. All rolling tests were performed in the dry state. The abrasion loss of the sample was measured by the gravimetric method with TG328A-type mechanical photoelectric analytic balance. The wear scar morphology and crack formation on the surface were observed using the light microscopy and the scanning electronic microscopy (SEM).

\section{Results and Discussion}

3.1. Relationship between Harness and Plastic Flow. Since for the high-speed railway rail, the main damage is contact fatigue, and in order to improve fatigue life of rail, we need to choose the rail material with better antifatigue performance. Here, the hardness and the resistance to plastic deformation
TABLE 1: Mass fraction of sample materials.

\begin{tabular}{lcccccc}
\hline \multirow{2}{*}{ No. } & \multicolumn{6}{c}{$w_{\mathrm{B}}(\%)$} \\
& $\mathrm{C}$ & $\mathrm{Si}$ & $\mathrm{Mn}$ & $\mathrm{P}$ & $\mathrm{S}$ & $\mathrm{V}$ \\
\hline PD3 quenched & 0.793 & 0.712 & 0.771 & 0.030 & 0.030 & 0.120 \\
PD3 hot rolled & 0.793 & 0.712 & 0.771 & 0.022 & 0.014 & 0.070 \\
U71Mn quenched & 0.736 & 0.282 & 1.400 & 0.020 & 0.030 & 0.040 \\
U71Mn hot rolled & 0.736 & 0.282 & 1.400 & 0.020 & 0.030 & 0.040 \\
\hline
\end{tabular}

of 4 kinds of materials were studied. Figure 1 shows the ratios of hardness for 4 kinds of rail materials.

In Figure 1, the quenched PD3 rail sample has the maximum hardness and the hot-rolled U71Mn rail sample has the minimum hardness before the test. With the same heat treatment process, the hardness of PD3 rail is greater than the hardness of U71Mn rail. With the same material, the hardness of quenched rail is greater than the hardness of hot-rolled rail.

After the rolling test, the hardness of several materials has increased. For the PD3 rail material which was provided with two heat treatment processes, the hardness increased less than $7 \%$ after the test. For the U71Mn rail material which was subject to quenched and hot-rolled treatment, the hardness increased by $19.1 \%$ and $20.9 \%$, respectively, after the test. With the same process, the increasing rate of hardness of U71Mn rail was far greater than that of PD3 rail before and after the test. With the same material, the increase of hardness rate of hot-rolled rail was slightly larger than the hardness rate of quenched rail before and after the test. It can be seen that, for the material with low hardness, the increasing rate of hardness was larger and the strain strengthening was more obvious after the wear test.

Because the carbon mass fraction of PD3 rail is greater than the carbon mass fraction of U71Mn rail and the rail performance is greatly affected by the carbon mass fraction, with the increase of carbon mass fraction, the number of pearlites gradually increases and the ductility and toughness decrease with the increase of strength and hardness. From the carbon mass fraction point of view, the strength and the hardness of PD3 are higher than the strength and the hardness of U71Mn, but the plasticity and the toughness are lower than the plasticity and the toughness of U71Mn. In addition, PD3 rail contains $\mathrm{Si}$ and $\mathrm{V}$. Since $\mathrm{Si}$ can decrease oxidation caused by friction heat and increase the cold deformation hardening rate of steel, addition of Si to the rail steels can improve the wear resistance. Trace amounts of $\mathrm{V}$ can improve the material strength by precipitation strengthening and pearlite refinement. Furthermore, $\mathrm{V}$ is an element forming strong carbide, and it can hinder the diffusion of carbon, so the carbon cannot diffuse by long range. That also makes the space between pearlites smaller [10]. The joint action of C, Si, and $\mathrm{V}$ makes the hardness and the strength of PD3 rail much higher than those of U71Mn rail.

To further study the plastic deformation of different rail materials in the rolling test, microstructure morphology analysis on the profile texture was performed for the abovementioned four material samples along the direction vertical to the rolling surface, as shown in Figure 2.

In Figure 2, it is shown that obviously, a plastic deformation layer appeared near the wear surface of several rails after the rolling test. When the wheel/rail surfaces 


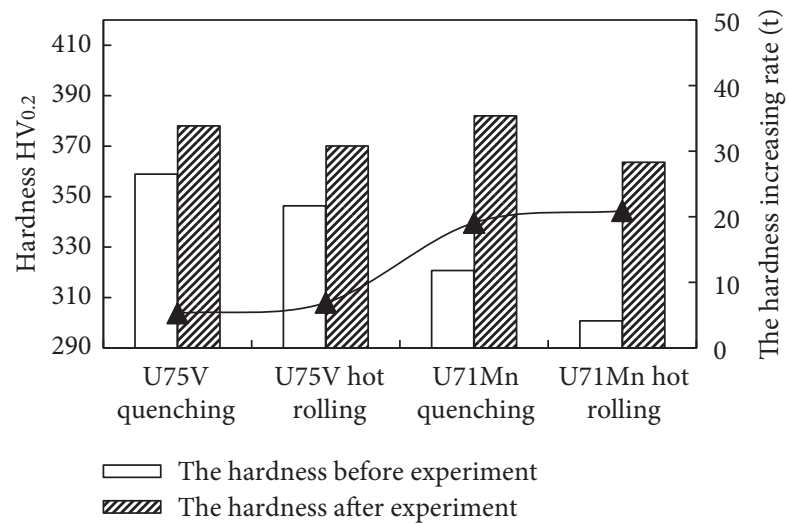

FIGURE 1: Comparison diagram of hardness of different rail materials.

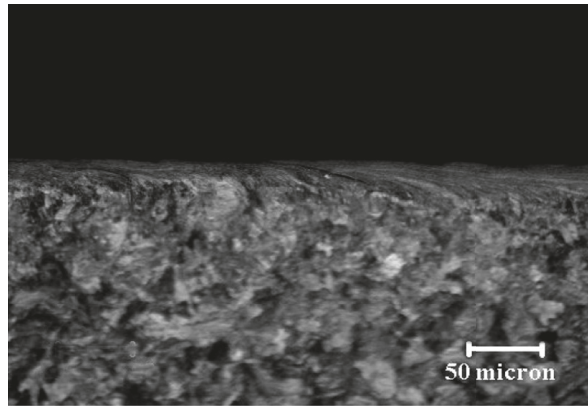

(a)

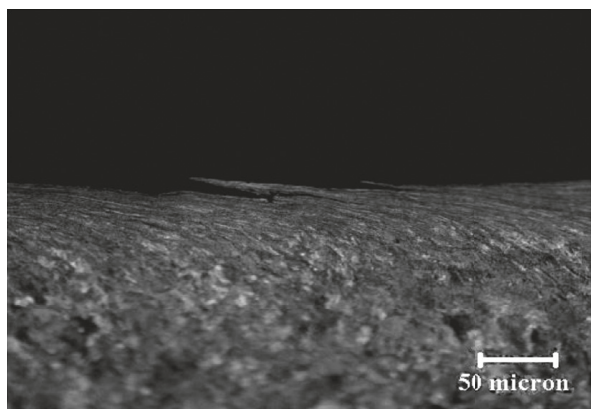

(c)

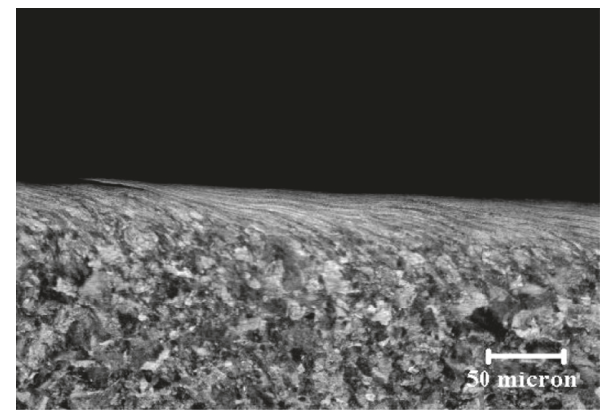

(b)

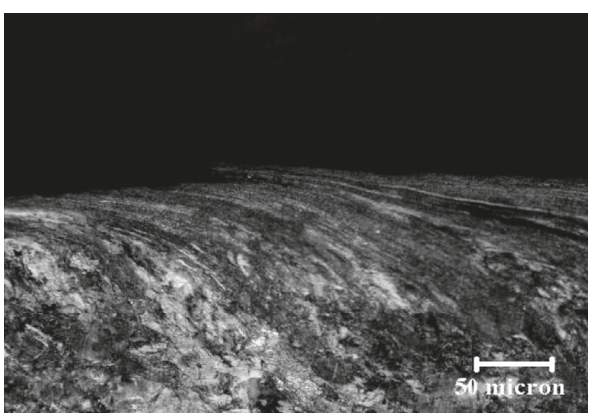

(d)

Figure 2: Plastic flow deformation of different rail samples: (a) quenched PD3 rail (200x); (b) hot-rolled PD3 rail (200×); (c) quenched U71Mn rail (200x); (d) hot-rolled U71Mn rail (200x).

contacted, the rail contact surface is subjected to high frictional force and the plastic flow deformation occurred on the metal of the rail surface along the wheel rolling direction. Each wheel rolling would lead to slip of the metal microstructure, and the accumulation of microstructure slip formed the plastic flow layer. The thickness of the plastic deformation layer could represent the wear degree of the material surface. The thicker the plastic deformation layer was, the severer the wear was. Fatigue cracks were generated from the rail surface and extended along the direction of plastic deformation. Both bending deformation and shear fracture existed in the pearlite structure near the cracks.

In Figure 2(a), it shows that the quenched PD3 rail material had the most nonobvious plastic deformation and had better resistance to plastic deformation. That means the wear was slight. However, the plastic deformation layer of hot-rolled PD3 rail shown in Figure 2(b) was thicker than the plastic deformation layer of quenched PD3 rail shown in Figure 2(a). As well, comparing Figure 2(c) with Figure 2(d), it can be known that the plastic deformation layer of quenched U71Mn rail was thinner than that of hot-rolled U71Mn rail. It can be seen that, when the materials were same, the resistance to plastic deformation of the quenching material was stronger than that of the hot-rolling material.

Figures 2(a) and 2(c) show that, comparing with quenched U71Mn rail, the plastic deformation layer of the quenched PD3 rail was thinner. Figures 2(b) and 2(d) show that the plastic deformation layer of hot-rolled PD3 rail was also thinner than that of hot-rolled U71Mn rail. It can be seen that, when the processes were same, the resistance to plastic deformation of the PD3 rail material was stronger than that of the U71Mn rail material. 
Therefore, it can be seen that the material of which the hardness is higher had a small change in hardness before and after the rolling test, and the plastic deformation was not obvious near the abrasion surface, so it has good antiwear properties. The hardness of the material with lower hardness increased greatly after the rolling test, and the plastic deformation was obvious near the wear surface with a thicker plastic flow layer. Experimental studies show that the change rate of hardness before and after the test determined the plastic deformation of the material.

3.2. Relationship between Fatigue and Wear. The relationship between wear and fatigue is mutual competition and restriction. When the wear is severe, the fatigue is slight relatively, and when the fatigue is severe, the wear is relatively slight. Severe wear surface can eliminate the microcracks on the surface. Hence, a certain degree of wear is allowable because it is an effective means to eliminate microcracks. Microcracks will likely lead to serious security issues. Paris gave the equation for growth rate of single crack and surface wear rate, particularly as shown below:

$$
\frac{d a_{\text {net }}}{d N}=\frac{d a}{d N}-\frac{w}{\sin \theta}=C(\Delta K)^{m}-\frac{w}{\sin \theta} .
$$

where $d a / d N$ is the growth rate of cracks with no wear; $d a_{\text {net }} / d N$ is the actual growth rate of cracks with wear; $w$ is the wear rate under the cyclic function of the unit load; $\theta$ is the angle between the cracks and plane; $C$ and $m$ are Paris constant and Erdogan constant, respectively; and $\Delta K$ is the crack stress intensity factor, and it is the net growth rate of cracks under cyclic function of the unit load. As shown in Figure $3, w / \sin \theta$ is the rate that the crack length is truncated, which is caused by the surface material wear, when the load goes through.

According to equation (1) and Figure 3, it can be seen that, for a single crack, it could continue to extend if the growth rate of crack tips was greater than the transection rate of crack roots due to the surface material wear when the wheel passed through. Conversely, with the increase of the number of wheel rolling, the crack length reduced continually, until the crack was completely worn away. Obviously, the crack growth rate depended on the stress intensity factor and the wear rate. Although many crack growth processes on the rail contact surface had a great influence on each other, there were resemblances between their mutual action during the growth process and wear process and the single crack. The fatigue fracture dominated in high-speed rail damage. Based on the coupling between the contact surface wear and crack growth of rail material samples, taking appropriate measures to increase the wear rate can effectively reduce the actual crack growth velocity of the rail material sample surface, so as to improve the fatigue life of rails. Therefore, it is a must to choose the rail material with good antifatigue property.

In order to research the relationship between the wear and the fatigue of different materials, the wear and fatigue of multiset samples of these four rail materials were analyzed in the test. Figure 4 shows the wear comparison of different materials after the wear test.

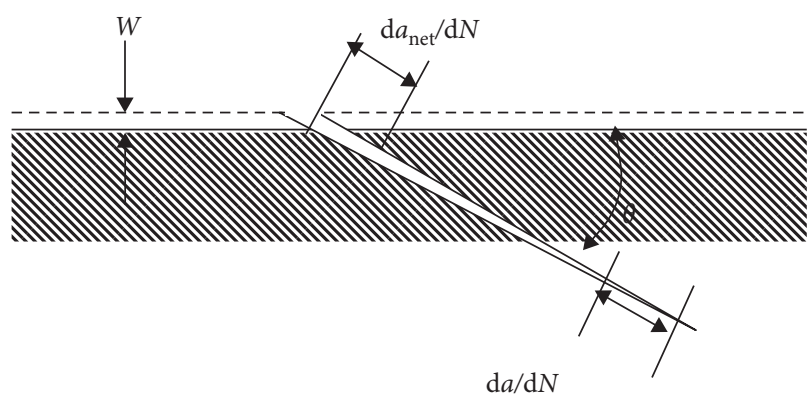

FIGURE 3: Diagram of the competitive relationship between wear and fatigue.

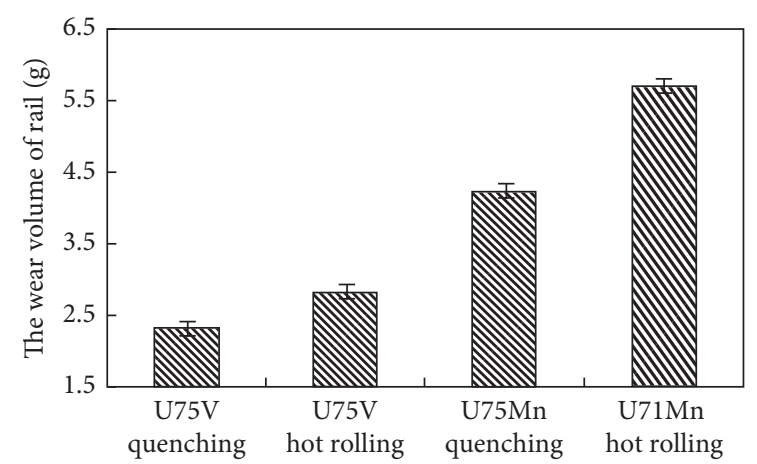

FIgURE 4: Wear loss of different materials.

It can be seen from Figure 4 that the wear resistances of the two materials (U71Mn and PD3) were quite different under different treatment processes (hot-rolling and quenching). Quenched PD3 rail had the smallest wear loss, and hot-rolled U71Mn rail had the biggest wear loss. The wear loss of hot-rolled PD3 material was 1.22 times of the quenched PD3 material. The wear loss of the hot-rolled U71Mn material was 1.35 times of the quenched U71Mn material. Thus, the wear loss of the hot-rolled rail material was greater than that of the quenched rail material when the materials were same. For the U71Mn material, the influence by the heat treatment process was more significant. Additionally, the wear losses of the U71Mn material were 1.82 and 2.01 times of the PD3 material, respectively, for the quenching process and hot-rolling process. Visibly, when the heat treatment processes were same, the wear loss of the U71Mn rail material was much larger than that of the PD3 rail material. Therefore, for the material which has low hardness, the wear loss was large, and the resistance to wear was poor after the wear test. For the material which has high hardness, the resistance to wear was good.

In order to research the fatigue of different materials, in the test, the sample was dissected along the vertical scrolling direction and the fatigue crack growth at the junction of the section and the wear scar surface was observed with SEM, as shown in Figure 5.

In Figure 5, it can be found that stripping traces existed on the wear scar surface of all rail samples. It could be found that cracks existed on each stripping root. Some cracks had grown to the direction of material depth. Through observing the 


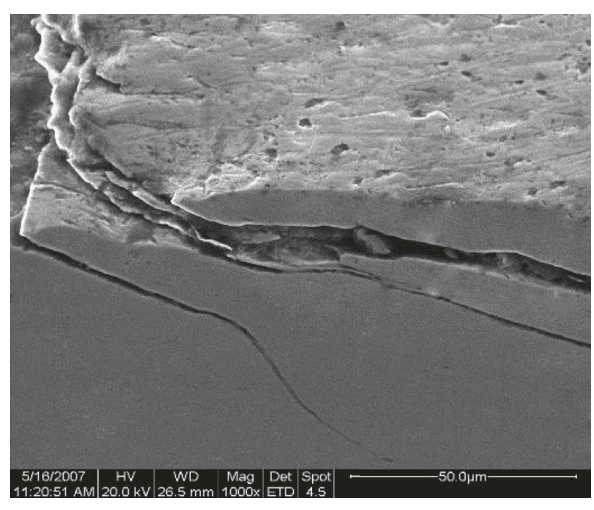

(a)

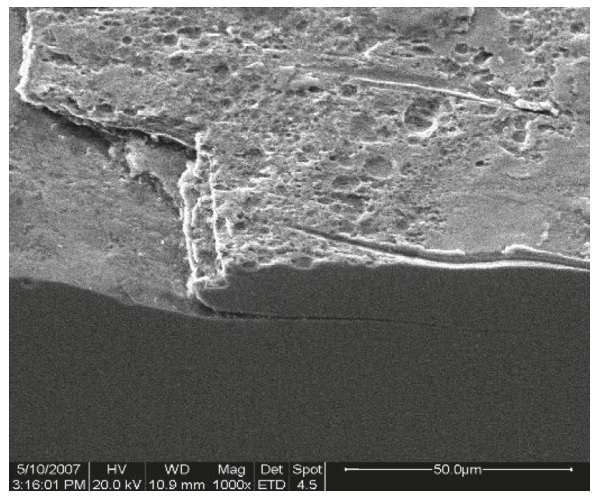

(c)

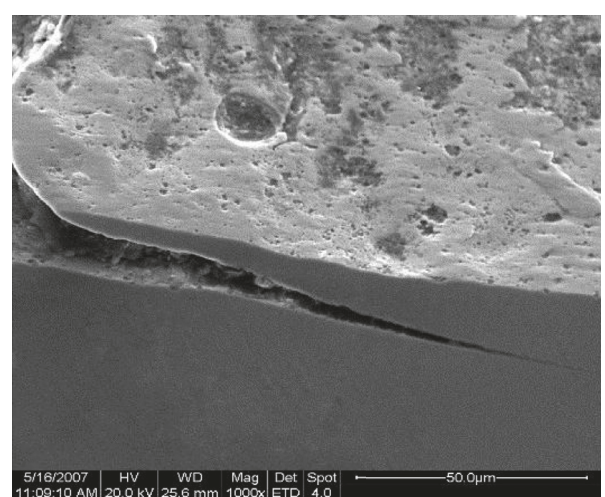

(b)

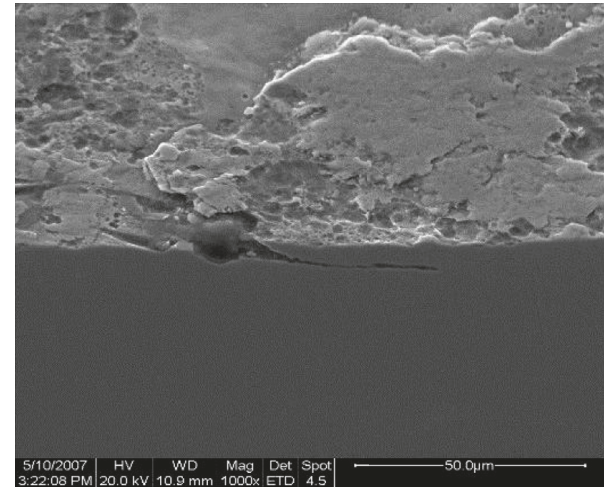

(d)

FIgURe 5: Crack growth of different rail material samples: (a) quenched PD3 rail (1000×); (b) hot-rolled PD3 rail (1000×); (c) quenched U71Mn rail (1000×); (d) hot-rolled U71Mn rail (1000×).

crack distribution morphology on the cross section, it can be found that cracks produced in the wear surface of the sample mainly. Some small cracks would continue to extend along a direction parallel to the surface after extending down to a certain depth, causing the surface of the sample exfoliated off.

In Figure 5(a), the surface of quenched PD3 rail was relatively smooth, but the cracks extended to the center of rail. Comparing with the quenched rail, the surface of the hotrolled PD3 material was relatively coarse and the crack propagation was relatively slight, as shown in Figure 5(b). In Figures 5(c) and 5(d), the surfaces of the two kinds of heattreated U71Mn materials were course with more fine flaking pits. These flaking pits were caused by severe material wear. Many samples showed that the cracks of hot-rolled U71Mn rail were shorter than those of quenched rail, and the growth depth was also shallower. It can be seen that, with the same composition, the fatigue crack growth of the quenched material was more serious than that of the hot-rolled material.

Comparing Figure 5(a) with Figure 5(c), it can be found that the crack depth of the quenched PD3 rail material was much deeper than that of quenched U71Mn rail and the cracks of quenched PD3 rail was easier to extend to the center of rail. Similarly, in Figures 5(b) and 5(d), the crack extension of hot-rolled PD3 rail was also deeper than that of quenched U71Mn rail.

Therefore, with the same heat treatment process, the crack extension depth of PD3 rail was significantly deeper than that of U71Mn rail. This means the resistance to fatigue damage PD3 rail was poor. Cracks of U71Mn rail under the surface basically extended along the direction parallel to the sample surface. It is not easy to cause serious harm to the use of rail. However, some cracks of the quenched PD3 material deepened to the interior of the sample, and the contact fatigue damage caused by that was often more serious.

Figure 5 shows that chunks of flaking debris existed on the surface significantly. That means, for surface wear, there were quite obvious adhesive wear and fatigue wear in addition to abrasive wear. If the wheel-rail contact stress exceeded the yield limit of the wheel-rail material, the plastic deformation of the material would take place. Under the action of repetitive loading, plastic deformation would accumulate and increase and microcracks would form on the surface and subsurface of material. Under the action of larger normal and tangential stress, microcracks extended along the direction of movement to the rail body.

In conclusion, it can be found the fatigue damage of the sample with small amount of abrasive loss was severe, and the fatigue damage of the sample with large amount of abrasive loss was relatively slight, as some newly initiated microcracks were rubbed off. This is consistent with Paris and Erdogan's research. With the same process, the resistance to fatigue of U71Mn rail was better than that of PD3 rail. With the same composition, the resistance to fatigue of hot-rolled rail was better than that of quenched rail. Therefore, when hot-rolled U71Mn rail is in service, moderate wear can rub out most microcracks formed on the 
worn surface, so its fatigue resistance is better and it is suitable for rails in high-speed railway.

\section{Conclusions}

(1) The increase rate of hardness before and after the test determines the plastic deformation of the material. For material with high hardness, the change in hardness is small before and after the rolling test and the plastic deformation is not obvious near the worn surface, so it has better wear resistance.

(2) There is competition between the wear and the fatigue. The fatigue damage of the sample with small amount of abrasive loss is severe, and the fatigue damage of the sample with large amount of abrasive loss is relatively slight, as some newly initiated microcracks are rubbed off.

(3) The main damage of high-speed rail is fatigue damage. Hot-rolled U71Mn rail has good fatigue resistance and is more suitable for use in high-speed rail laying.

\section{Data Availability}

The data used to support the findings of this study are available from the corresponding author upon request.

\section{Conflicts of Interest}

The authors declare that they have no conflicts of interest.

\section{Acknowledgments}

This material is based on the work which was supported by National Natural Science Foundation of China (51405395), Ministry of Education (JYBFX-YQ-1 and szjj2016-010), and the Key Scientific Research Fund of Xihua University (z1410211).

\section{Supplementary Materials}

The data of hardness change before and after the experiment are provided. With the same material, the hardness of quenched rail is greater than the hardness of hot-rolled rail. After the rolling test, the hardness of several materials has increased. For the material with low hardness, the increasing rate of hardness was larger and the strain strengthening was more obvious after the wear test. (Supplementary Materials)

\section{References}

[1] A. C. Athukorala, D. V. De Pellegrin, and K. I. Kourousis, “A unified material model to predict ratcheting response in headhardened rail steel due to non-uniform hardness distributions," Tribology International, vol. 111, pp. 26-38, 2017.

[2] W. Zhong, L. Dong, J. J. Hu, and Y. Wang, "Experimental investigation of the matching relationship of different material wheel," Journal of the Balkan Tribological Association, vol. 21, no. 4, pp. 850-856, 2015.
[3] H. P. Marchenko, "Influence of residual stresses on the stress intensity factors for a surface crack in the rail head," Materials Science, vol. 46, no. 1, pp. 64-69, 2010.

[4] R. M. Nejad, M. Shariati, and K. Farhangdoost, "Effect of wear on rolling contact fatigue crack growth in rails," Tribology International, vol. 94, pp. 118-125, 2016.

[5] P. E. Bold, M. W. Brown, and R. J. Allen, "Shear mode crack growth and rolling contact fatigue," Wear, vol. 144, no. 1-2, pp. 307-317, 1991.

[6] J.-W. Seo, H.-K. Jun, and S.-J. Kwon, "Rolling contact fatigue and wear of two different rail steels under rolling-sliding contact," International Journal of Fatigue, vol. 83, pp. 184194, 2016

[7] A. A. Razhkovskiy, T. G. Bunkova, and A. G. Petrakova, "Optimization of hardness ratio in rail-wheel friction pair," Journal of Friction and Wear, vol. 36, no. 4, pp. 334-341, 2015.

[8] S. Sharma, S. Sangal, and K. Mondal, "Wear behaviour of bainitic rail and wheel steels," Materials Science and Technology, vol. 32, no. 4, pp. 266-274, 2016.

[9] X. Y. Feng, F. C. Zhang, and J. Kang, "Sliding wear and low cycle fatigue properties of new carbide free bainitic rail steel," Materials Science and Technology, vol. 30, no. 12, pp. 14101418, 2014.

[10] W. Zhong, J. J. Hu, P. Shen, C. Y. Wang, and Q. Y. Liu, "Experimental investigation between rolling contact fatigue and wear of high-speed and heavy-haul railway and selection of rail," Material Wear, vol. 271, no. 9-10, pp. 2485-2493, 2011. 


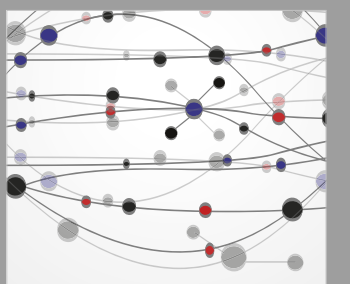

The Scientific World Journal
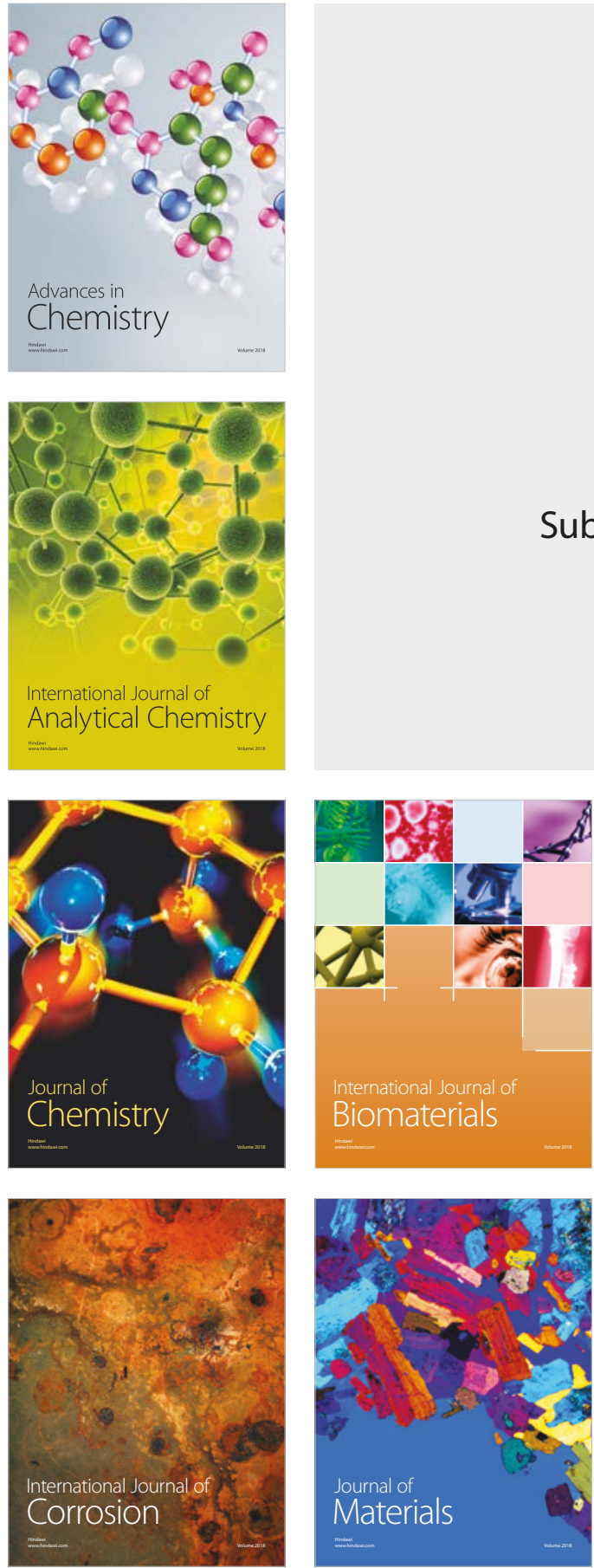

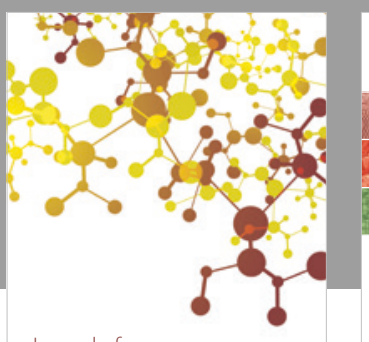

Journal of

Applied Chemistry
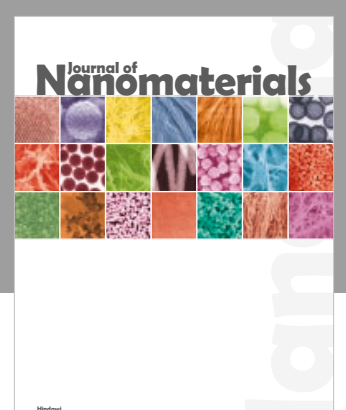

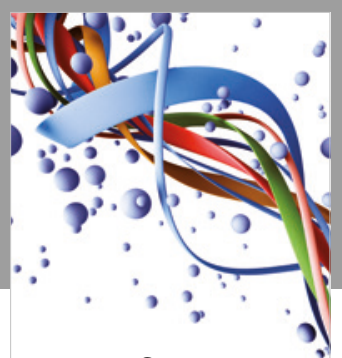

Scientifica

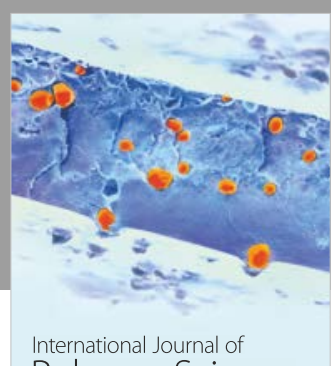

Polymer Science

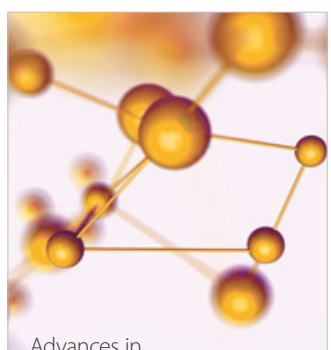

Physical Chemistry
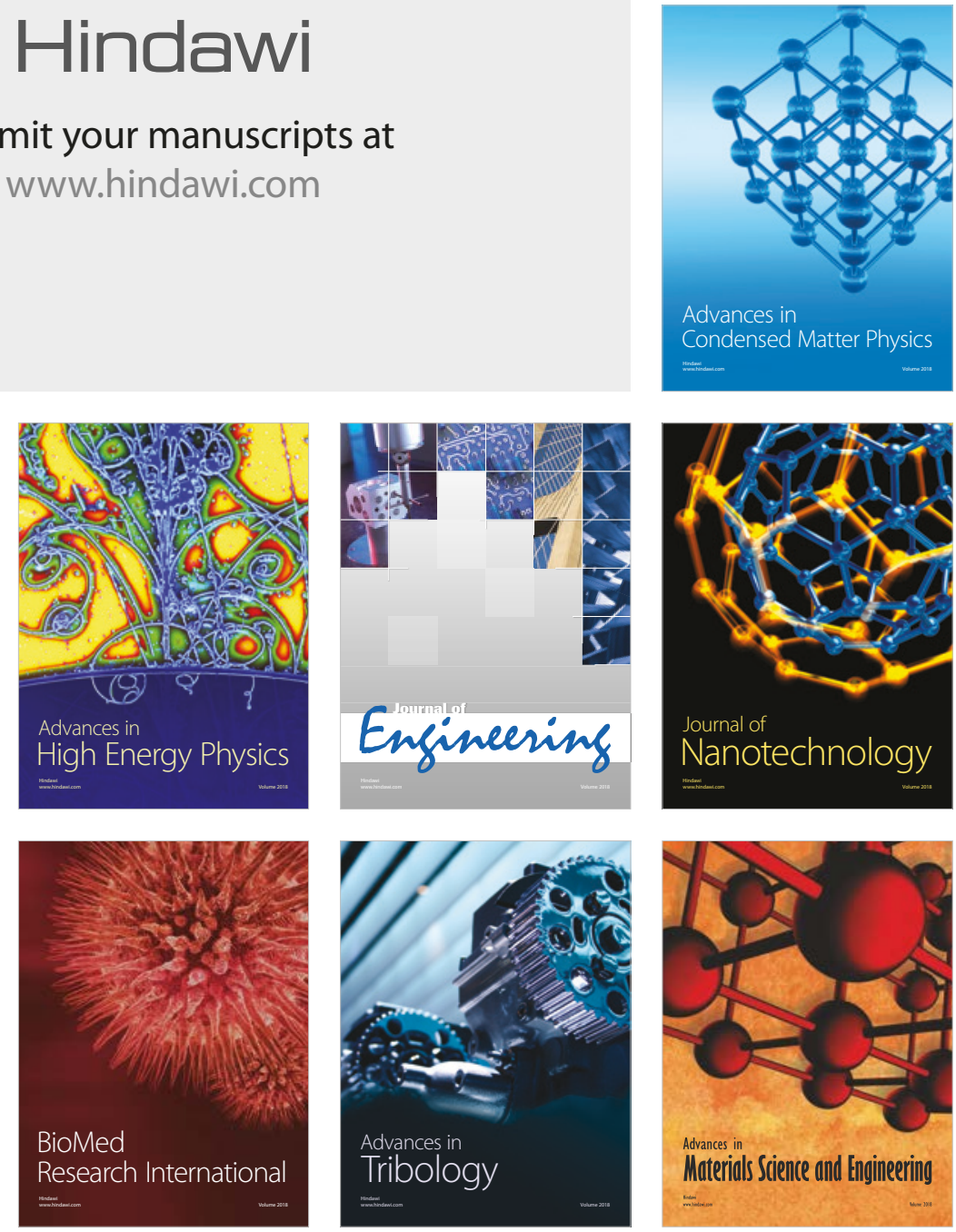